\title{
Panel Survey of Young People in Egypt (SYPE) 2014: Generating Evidence for Policies and Programs-Summary Report
}

Rania Roushdy

Population Council

Maia Sieverding

Follow this and additional works at: https://knowledgecommons.popcouncil.org/departments_sbsr-pgy

Part of the Demography, Population, and Ecology Commons, Family, Life Course, and Society Commons, and the International Public Health Commons How does access to this work benefit you? Let us know!

\section{Recommended Citation}

Roushdy, Rania and Maia Sieverding. 2015. "Panel Survey of Young People in Egypt (SYPE) 2014:

Generating evidence for policy, programs, and research-Summary Report." Cairo: Population Council. 


\section{POPULATION COUNCIL}

Ideas. Evidence. Impact.

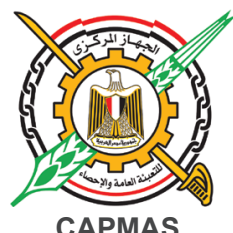

CAPMAS

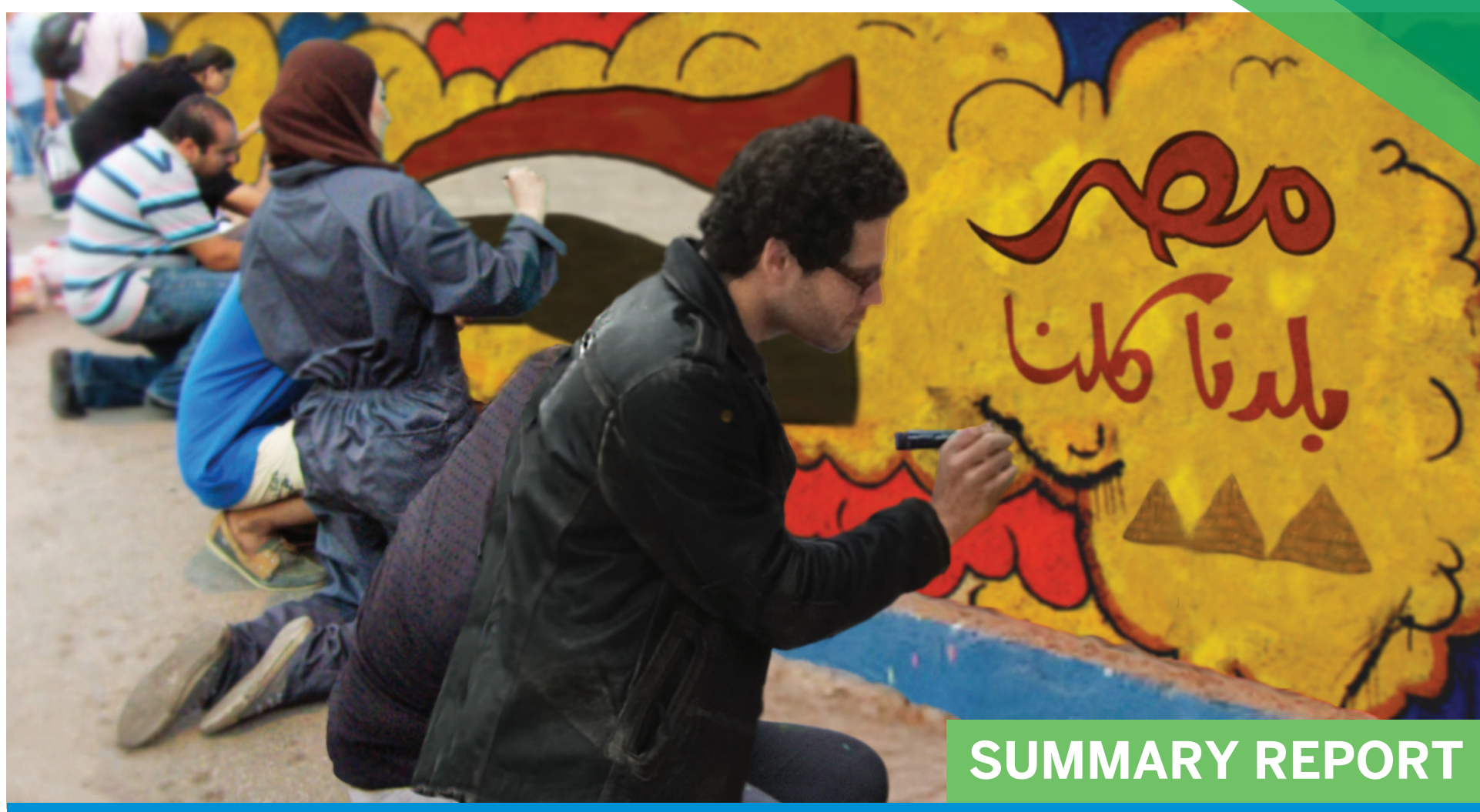

PANEL SURVEY OF

YOUNG PEOPLE IN EGYPT

(SYPE) 2014

Generating Evidence for Policy,

Programs, and Research

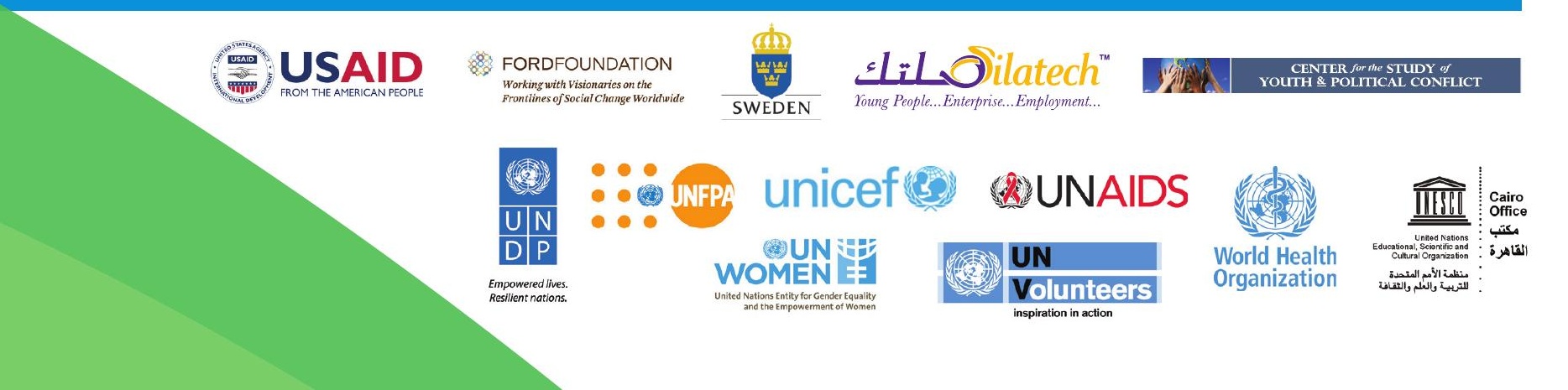




\section{PoPULATION pouncil \\ Ideas. Evidence. Impact.}

The Population Council confronts critical health and development issues-from stopping the spread of HIV to improving reproductive health and ensuring that young people lead full and productive lives. Through biomedical, social science, and public health research in 50 countries, we work with our partners to deliver solutions that lead to more effective policies, programs, and technologies that improve lives around the world. Established in 1952 and headquartered in New York, the Council is a nongovernmental, nonprofit organization governed by an international board of trustees.

Population Council

One Dag Hammarskjold Plaza

New York, NY 10017

Population Council/Egypt

59 Misr-Helwan Agricultural Road, Maadi

PO Box 168, Maadi

Cairo, Egypt 11431

Tel. +20225255968

Fax: +20225255962

\section{popcouncil.org}

Suggested citation: Roushdy, Rania and Maia Sieverding. 2015. "Summary Report: Panel survey of young people in Egypt 2014-Generating evidence for policy, programs, and research." Cairo: Population Council.

This report summarizes the findings from "Panel survey of young people in Egypt 2014-Generating evidence for policy, programs, and research." The opinions expressed herein are those of the authors and do not necessarily reflect the views of the initiative supporters.

Photo credit: Wolfgang Sterneck/Salma Abou Hussein

Any part of this publication may be photocopied without permission from the Population Council provided that copies are distributed without charge and that full source citation is provided. The Population Council would appreciate receiving a copy of any materials in which the text is used.

(C) 2015 The Population Council, Inc. 


\section{Contents}

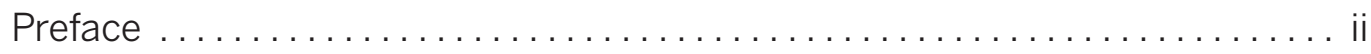

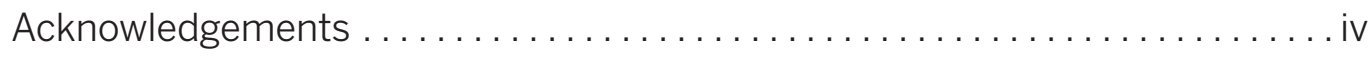

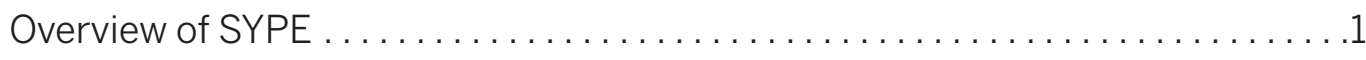

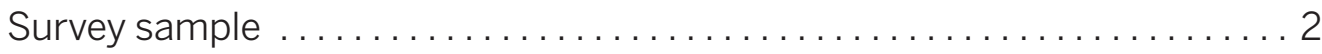

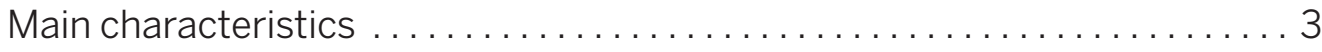

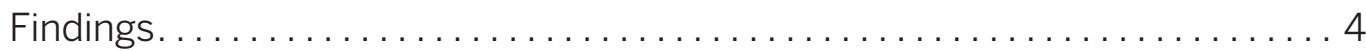

Health and safety $\ldots \ldots \ldots \ldots \ldots \ldots \ldots \ldots \ldots \ldots \ldots \ldots \ldots \ldots \ldots$

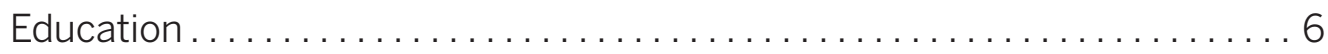

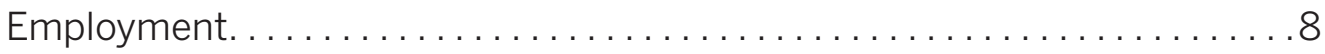

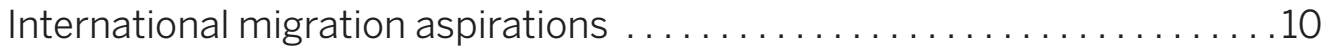

Marriage and family formation $\ldots \ldots \ldots \ldots \ldots \ldots \ldots \ldots \ldots \ldots \ldots \ldots$

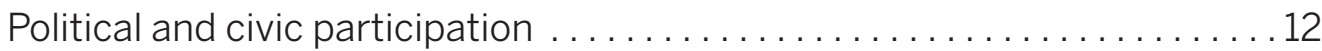

Young people's attitudes toward gender roles ................... 13

Conclusion and policy implications.......................... 15

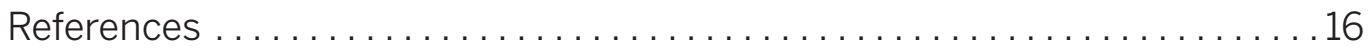




\section{Preface}

The youth phase is one of the most crucial times in a person's lifetime, in which an individual shifts from being a child to becoming an adult. It is the progression from the dependence on parents in livelihood matters and decision making to increasing independence. During this period, a person is exposed to experiences and information that help shape his/her own self-identity and personal beliefs and enables him/her to make choices and form judgments that would guide his/her present and future. It is also the transitional phase from school to the job market and all it holds of challenges, future aspirations and endless opportunities.

In any society youth constitute the engine of growth and development and they are the leaders of tomorrow. Today's youth shape the future of the country and take on the responsibility of meaningfully contributing to the rebuilding of our nation. Recent development experiences have demonstrated the pivotal role that youth play in achieving development goals.

Youth are considered reservoirs of strength, knowledge and infinite energy, hence they are capable of easily adapting to the rapid technological advancements happening around the world. Many societies seek to utilize these pulsating energies in increasing employment, aggregating production and achieving development goals through providing adequate job opportunities and creating an enabling environment for young people to be creative and innovative as well as involving them in the decision making process. On the other hand, marginalizing this population group during this critical phase of their life may in turn lead to negative outcomes both at the personal level and for society at large. Unemploy- ment, drug use, decadence and lack of a sense of citizenship and national belonging are some of the serious consequences of marginalizing youth. Therefore, it is of utmost importance to integrate youth in society through understanding their problems and assisting them in successfully addressing them.

The Egyptian population is exceptionally young with about $61 \%$ under the age of 30 ; and $40 \%$ of the population between the ages of 10 and 29 , being equally distributed among males and females. This population could be perceived as a challenge for the Egyptian government in providing education and health services, suitable housing and employment opportunities to accommodate the needs of this massive generation of young people. It could also be seen as a demographic opportunity of huge potential for achieving progress and prosperity for the country if those massive human resources are properly utilized and directed towards work, production and active participation in building this nation.

From this standpoint comes the importance of the Survey of Young People in Egypt (SYPE), which was first conducted in 2009. The survey is the first of its kind conducted on youth of ages between 10 and 29 and focuses on key aspects of their lives including education, employment, health, family formation, migration, reproductive health, social issues and civic/political participation. The second round of the survey was conducted in 2014 in the wake of major transitions that took place in Egypt with the outbreak of two youth-led revolutions (January 25, 2011 and June 30,2013 ) calling for freedom, social justice and equality. Moreover, the Survey gains additional importance from the fact that it attempts to un- 
derstand changes that occurred among Egyptian youth over the period between the two rounds through targeting the same group of respondents of the 2009 survey in 2014 to accurately document changes and progress in the status of these young people.

Preliminary findings of SYPE 2014 indicated that positive improvements have occurred in a number of areas compared to the 2009 round. A slight decrease in unemployment among this age group was noticeable as well as a reduction in rates of early marriage, although early marriage remains one of the major problems in our society. The gender gap in educational attainment has narrowed in the period between the two surveys. Despite political and economic instability between 2011-2013 youth desire to migrate has not changed between the two surveys while youth participation in social and political activities is on the rise.

Moreover, prevalence rates of female genital mutilation/cutting and sexual harassment appear to be declining. On the other hand, youth are increasingly seeing their immediate environment as polluted, and perceiving streets and public transportation as unsafe. SYPE has also highlighted that Egyptian youth aspire to improve their living conditions and to fight corruption and achieve freedom and democracy. While there is a general feeling of dissatisfaction with living conditions in Egypt over the last few years, young people expressed their optimism about the future.
With no doubt, the Egyptian youth have demonstrated their huge potential and capabilities that need to be invested in for reforming the nation and contributing to its welfare and prosperity. This entails providing youth with the necessary opportunities to acquire a broad range of competencies and creating a suitable environment that would ensure their skills development and political inclusion. Therefore, the Government of Egypt is expected to sustain their efforts in reaching these goals while youth are expected to work on strengthening their own skills and nurturing their innate capabilities for creativity and innovation.

To conclude, I would like to thank all those who contributed to this survey both at the Population Council and the Central Agency for Public Mobilization and Statistics (CAPMAS), for their efforts to complete this body of work. We hope the findings of this survey would assist in setting a roadmap to enhance the current situation of Egyptian youth and in delivering an array of related activities that would fulfill their aspirations and dreams for the future. We are hopeful that young people of Egypt will play a greater role in the development of our nation in the coming period.

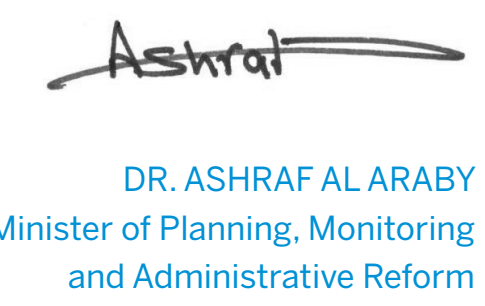




\section{Acknowledgements}

The 2014 wave of the Panel Survey of Young People in Egypt (SYPE 2014) would not have been possible without the support and commitment of a number of individuals and institutions. His Excellency Minister Ashraf Al Araby has supported the survey throughout various phases and has shown keen interest in utilization of the results. The Central Agency for Public Mobilization and Statistics (CAPMAS) team, under the leadership and guidance of General Abou Bakr El Gendy, has competently and diligently managed all data collection and processing activities related to this survey and made valuable contributions during the review and pretesting of SYPE questionnaires.

Special thanks are due to the following organizations for their generous financial support of the 2014 SYPE: USAID, Ford Foundation, SIDA, UNFPA, UNICEF, UNDP, UN WOMEN, UN Volunteers, UNAIDS, UNESCO, WHO, Silatech, and University of Tennessee.

We are grateful to government officials, researchers, partners and youth leaders who contributed to updating the 2014 survey questionnaires during the series of consultative meetings held by the Population Council in April 2013. Special thanks go to Dr. Ragui Assaad, Professor of Public Policy at the University of Minnesota and former Regional Director of the Population Council's West Asia and North Africa office, who initiated the 2009 SYPE and who continued to provide technical guidance at various stages of 2009 and 2014 surveys.
We also gratefully acknowledge the contributions of Dr. Brian Barber, at the Center for the Study of Youth and Political Conflict, University of Tennessee, and his team of collaborators on the Jacobs Foundation- funded project, for their significant contribution to the civic engagement module of the SYPE 2014. The technical support provided by colleagues at partner UN agencies is deeply acknowledged.

SYPE - 2014 has been undertaken by Population Council /Egypt Poverty, Gender and Youth Program. Dr. Rania Roushdy, Senior Program Manager, deserves special thanks for capably leading all survey activities and compiling the final report. Our sincere gratitude goes to all authors who contributed to this report as well as Dr. Maia Sieverding who has thoroughly reviewed and edited earlier drafts of this report. Thanks are also extended to Mr. Ali Rashed for managing all data analysis activities, Ms. Aya El Defrawy for providing logistical and administrative support to the project, and Robert Heidel and Michael Vosika for the copyediting and design of this report.

Last but not least, we wish to extend our sincere thanks and gratitude to the young people who responded candidly and enthusiastically to the 2014 survey. We are hoping that results of this survey will contribute to policies and programs that help young people in Egypt realize their dreams and full potential.

NAHLA ABDEL-TAWAB, MD, DRPH Country Director 


\section{Overview of SYPE}

In 2014 the Population Council in partnership with the Central Agency for Public Mobilization and Statistics (CAPMAS) collected the second round of data for the Survey of Young People in Egypt (SYPE) following the initial 2009 SYPE round. The objective of SYPE 2014 is to update the state of knowledge on adolescents and youth in Egypt and identify issues of importance to youth in the country's new political environment. SYPE is also intended to support policymakers in the development of evidence-based policies and programs to enhance the potential and well-being of Egyptian youth.

The 2009 SYPE generated data on the situation of youth in Egypt, covering areas important to the transition to adulthood, including education, employment, migration, health, family formation, social issues, and civic and political participation. To observe how young people have been faring following the transition period in Egypt, the second wave of SYPE reinterviewed the same sample of young people that was interviewed in 2009.

Our analysis of both waves of SYPE data provides a unique before-and-after picture of the economic, social, political, and health situation of young people during this critical period in Egypt's history.

This report summarizes the main results of SYPE. * The complete analysis is available in the SYPE final report, which can be downloaded at: popcouncil.org/SYPE2014

* A more detailed analysis and results are included in the SYPE 2014 final report. The final report was prepared by a team led by Rania Roushdy and Maia Sieverding. Co-authors of the final report include (in alphabetical order): Nahla Abdel-Tawab, Sarah Ismail, Caroline Krafft, Dafine Papoutsaki, Ahmed Ragab, Nada Ramadan, Ali Rashed, Colette Salemi, Irene Selwaness, Laila Sheira, and Jackline Wahba. 


\section{SURVEY SAMPLE}

SYPE 2009

- A nationally representative sample of 15,029 young people aged $10-29 .{ }^{1}$

- Included youth from 11,372 households across all governorates in Egypt (including Frontier Governorates).

- Informal urban areas were included as part of the urban sample.

SYPE 2014

- 10,916 young people who participated in SYPE 2009 (72.6\%) were interviewed.

- Data collection in the non-Frontier Governorates started in late 2013 and continued until February 2014. Because of security concerns, data collection in the Frontier Governorates was delayed until March 2014 and ended in June 2014.

- Every effort was made to track down the current location of households and/or eligible young people who had moved since the 2009 interview.

- Weights based on the probability of nonresponse were constructed to adjust the sample of the 2014 SYPE for attrition. This adjustment yielded a panel data set that is nationally representative for both time periods. ${ }^{2}$

1 Data collection for SYPE 2009 was conducted in collaboration with the Information and Decision Support Center of the Egyptian Cabinet.

2 In the SYPE 2014 final report, the authors use a variety of approaches to compare the two SYPE waves. Comparative analyses mainly focus on the 15-29 age group that is common across the two surveys, using the two cross-sectional waves. For some analyses, the authors rely on the panel dimension of SYPE to examine change in outcomes among the same group of youth as they age; for example, transitions in labor market status, migration aspiration, or marriage. Forthcoming in-depth papers and policy briefs under the SYPE project will make more use of the SYPE panel structure. 


\section{Main characteristics of SYPE 2014 respondents}

As a result of the high fertility rates experienced in the 1980s, accompanied by a decline in child mortality, Egypt has been experiencing a significant "youth bulge" at this stage in its demographic transition. According to SYPE 2009, 62\% of the Egyptian population was below age 29 at the time of data collection and almost $40 \%$ were between ages 10 and 29 .

Among 10-29-year-olds, the highest percentage of young people was in the age group from 10-17 in 2009 (44.7\%). In SYPE 2014, almost $42 \%$ of the youth sample is between ages 15 and 24 . The sample has now largely aged out of the youngest age group (10-14) that was captured in the SYPE 2009 , and $16.8 \%$ of youth are now in the $30-35$ age group that was outside the range of SYPE 2009 (Table 1).
Among the population aged $13-35$, the percent of males $(51.2 \%)$ is slightly higher than females (48.8\%). ${ }^{3}$ The majority of young people still reside in rural areas $(60.7 \%)$, as was the case in 2009. Nearly the same percentage of youth reside in informal urban areas in 2014 (9.8\%) as they did in 2009 (9.5\%); in contrast, fewer youth now live in urban areas (29.5\% in 2014 vs. $31.6 \%$ in 2009). Also, as in 2009, most young people reside in Lower Egypt (42.8\%) and Upper Egypt (36.7\%). The Urban Governorates contain about $18.7 \%$ of the young population, while only $1.8 \%$ live in the Frontier Governorates as of 2014.

3 Data collection for SYPE 2014 started in late 2013 and continued until mid-2014. So, respondents should be aged 14-34 during the second interview. However, it seems that some respondents were below age 10 or above age 29 during the 2009 interview, but misreported (or approximated) their age. This often occurs at the boundaries of the eligible age group in surveys. In the main report, the age is left as reported during the 2013-2014 interview without any adjustment.

TABLE 1 Weighted and unweighted distribution of young people by main background characteristics, 2014

\begin{tabular}{lccc}
\hline & WEIGHTED \%* & WEIGHTED (N) & UNWEIGHTED (N) \\
\hline Gender & & & $(5,336)$ \\
Male & 51.2 & $(5,586)$ & $(6,102)$ \\
Female & 48.8 & $(5,330)$ & $(2,196)$ \\
Age & & & $(4,158)$ \\
$13-17$ & 20.4 & $(2,227)$ & $(2,564)$ \\
$18-24$ & 39.5 & $(4,311)$ & $(1,998)$ \\
$25-29$ & 23.3 & $(2,539)$ & $(6,313)$ \\
30-35 & 16.8 & $(1,837)$ & $(4,593)$ \\
Marital status & & & $(2,064)$ \\
Never married & 64.8 & $(7,072)$ & $(1,217)$ \\
Ever married & 35.2 & $(3,834)$ & $(3,426)$ \\
Region & & & $(639)$ \\
Urban Governorates & 18.7 & $(2,043)$ & $(2,621)$ \\
Urban Lower Egypt & 11.6 & $(1,262)$ & $(952)$ \\
Rural Lower Egypt & 31.2 & $(3,407)$ & $(878)$ \\
Urban Upper Egypt & 8.0 & $(3,127)$ & $(3,314)$ \\
Rural Upper Egypt & 28.7 & $(199)$ & $(6,506)$ \\
Frontier Governorates & 1.8 & $(3,221)$ & $(1,099)$ \\
Urban-rural residence & & $(6,623)$ & $(10,916)$ \\
Urban & 29.5 & $(1,072)$ & $(10,916)$ \\
Rural & 60.7 & 9.8 & \\
Informal urban areas & 100.0 & & \\
Total & & & \\
\hline
\end{tabular}

*Weighted percentage is presented throughout this report, because it reflects the actual population, while the unweighted percentage reflects the sample. 


\section{Findings}

\section{Health and safety}

\section{HEALTH AND THE ENVIRONMENT}

Egyptian youth consider themselves healthier in 2014 compared to 2009, with about half (48.4\%) of respondents indicating that their health was either "very good" or "excellent" compared to less than a third (29.4\%) in 2009. When they became ill, fewer young people in 2014 sought medical care (71.5\% versus $88.9 \%$ in 2009$)$ and fewer utilized public hospitals (14.6\% in 2014 versus $26.5 \%$ in 2009 ) or private clinics or hospitals (39.2\% in 2014 versus $45.8 \%$ in 2009 ).

About two-thirds (67.6\%) of respondents perceived the environment around them as polluted, a substantial increase from the $29.6 \%$ documented in 2009. Among those respondents, $60.7 \%$ believed pollution affected their health in the form of respiratory and digestive problems, eye infections, skin rashes, and hearing problems.

\section{EXPOSURE TO RISK}

Security issues, together with decreased presence of police on the streets and inadequate law enforcement during the transitional period, have taken their toll on young people. Some $70.2 \%$ indicated they faced at least one serious risk on the street, and $81.6 \%$ felt they were exposed to at least one form of risk while on public transportation. Risks included crowding, fast or reckless driving, theft, and aggressive drivers. Moreover, young bicycle or motorcycle riders did not take active measures to protect their personal safety through the use of helmets or the use of seatbelts by drivers or passengers. In fact, seatbelt use dropped among SYPE drivers from $45.5 \%$ in 2009 to $21.3 \%$ in 2014 and among passengers from $7.7 \%$ to $3.5 \%$. This decrease may be due to weak law enforcement following the January $25^{\text {th }}$ Revolution.

Young women in 2014 continue to be exposed to sexual harassment on the street and on public transportation, albeit in slightly smaller proportions than in 2009 (Figure 1). An overall decrease in sexual harassment has been noted among female youth 13-29 (from 49.7\% in 2009 to $42.8 \%$ in 2014). However, young girls aged 13-17 witnessed a slight increase in exposure to sexual harassment (from $46.4 \%$ in 2009 to $49.5 \%$ in 2014). Sexual harassment was most common in informal urban areas, Urban Governorates, and urban Upper and Lower Egypt. Besides being a violation of girls' rights, sexual harassment may lead to further limitation of girls' mobility and exclusion from public domains.

\section{NUTRITION, DIETARY HABITS, AND PHYSICAL} ACTIVITY

Poor eating habits, coupled with smoking and lack of physical exercise, expose young people to health risks such as obesity, hypertension, and diabetes. More than half of young people aged 13-35 (51.6\%) drink carbonated beverages 1-3 times per week, while more than one-third

FIGURE 1 Exposure to sexual harassment among females aged 13-29, 2009 and 2014 (\%)

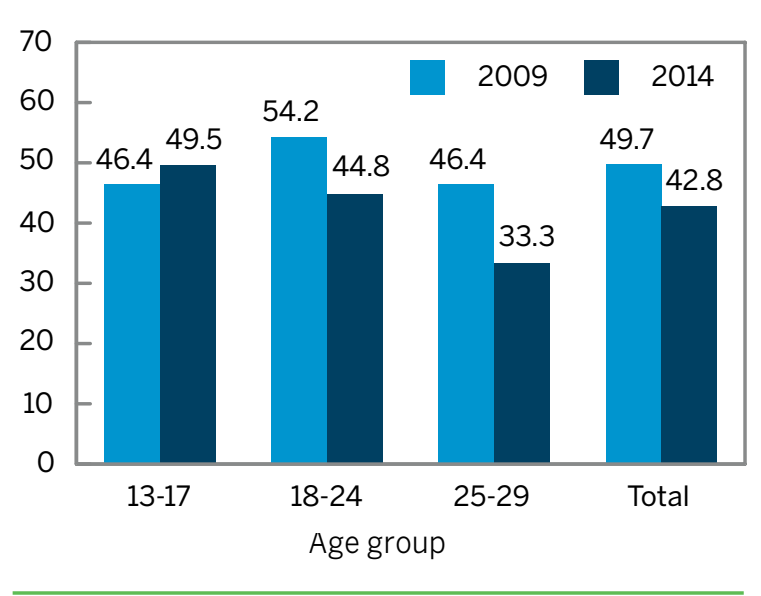


(35\%) eat fast food 1-3 times per week. Young males, those who live in Urban Governorates, and those in the highest wealth quintile tend to consume more carbonated drinks and fast food than other groups.

More than one-quarter (28.0\%) of male youth aged $13-35$ reported currently smoking cigarettes occasionally or regularly. Current smoking increased with age, from $5.6 \%$ of $13-17$-yearold males to $46.9 \%$ among 30-35-year-olds. Engagement in physical activity, such as walking or cycling to work/school or playing sports, is limited among young people aged 15-29 with slightly over half (54.9\%) of respondents reporting that they engage in daily physical activity (Figure 2). Young women are much less likely to exercise daily than men $(40.8 \%$ and $67.8 \%$ respectively).

\section{REPRODUCTIVE HEALTH AND KNOWLEDGE OF HIV/AIDS}

Discussion of pubertal changes with parents is low, with just over one-third of young people aged 13-35 reporting that they had ever discussed puberty, reproductive health, or sexual relations with a parent. More than twice as many female respondents (47.5\%) as male respon-

FIGURE 2 Engagement in daily physical activity among youth aged 15-29, by gender, 2009 and 2014 (\%)

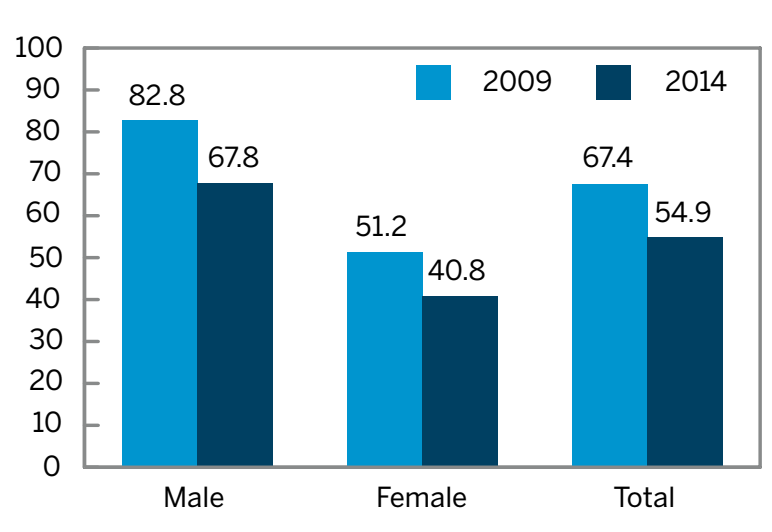

\section{More than one-third of female SYPE} respondents aged 13-35 were exposed to some form of sexual harassment in 2014.

dents (21.6\%) had spoken with a family member about puberty. The percentage of male respondents (aged 15-29) who had talked with their parents about puberty increased substantially between 2009 and 2014 (from 8.1\% to 21.4\%). In the absence of credible sources of information, young people may turn to their peers, the internet, or mass media, which may not provide accurate information.

Young people have limited knowledge about HIV or its modes of transmission. ${ }^{4}$ Slightly less than three-quarters of SYPE 2014 respondents had heard of HIV/AIDS (73.2\%); of those who had heard of HIV/AIDS, slightly more than one-third (35\%) know 3-4 modes of transmission while fewer than one in five respondents are willing to interact with someone living with HIV. Knowledge of HIV/AIDS declined between 2009 and 2014 (from $85.5 \%$ to $73.6 \%$ among youth aged $15-29$ ) and is lower among women, younger age groups, and those with no education. With such low levels of information and high levels of stigma associated with the disease, young people may not be able to protect themselves, their spouses, or future offspring against HIV infection.

The prevalence of female genital mutilation/cutting $(F G M / C)$ continues to raise concerns. Fewer female SYPE respondents aged 15-29 indicated in 2014 that they were cut, compared to 2009

4 Knowledge of HIV/AIDS is measured through several questions. First, SYPE respondents were asked, "Have you ever heard of any sexually transmitted infections (STIs)?" and "What type of STIs you have heard about?" Second, SYPE respondents who indicated that they had not heard of any STIs were asked, "Have you ever heard of AIDS?" 
FIGURE 3 Response of females aged 15-29 to question whether they had been circumcised, 2009 and 2014 (\%)

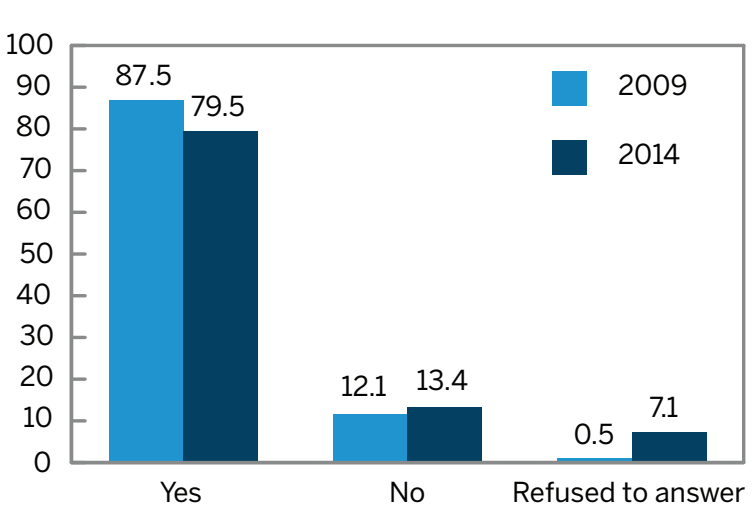

(79.5\% versus $87.5 \%)$. However, more respondents in 2014 refused to answer this question (7.1\% vs. $0.5 \%$ ) (Figure 3 ). ${ }^{5}$ Moreover, 6 out of 10 young people (male and female) believe the practice is necessary while 7 out of 10 intend to circumcise their future daughter. Refusal to answer a question about FGM/C status may suggest ambivalence about the practice or fear of legal implications for themselves or their parents among girls who have been circumcised. These findings call for interventions that target young people early enough before they get married and subject their daughters to this practice.

Awareness of family planning methods is fairly high with over half (61.5\%) of respondents indicating knowledge of family planning methods that could delay or prevent pregnancy. However, knowledge was considerably lower among male youth (52\%), younger people aged 13-17 (34.8\%), and those who are not married (45.2\%).

Also, contraceptive use among currently married young people is relatively low (42.6\%). Current use is lowest among 13-17-year-old married youth (10.1\%) and highest among 30-

5 If we focus only on those who answered the question about circumcision status (i.e., excluding those who refused to answer), the percentage who said they were cut is $87.9 \%$ in 2009 compared to $85.6 \%$ in 2014
35 year old respondents (50.9\%). The last figure is substantially lower than the rate of $64.6 \%$ reported by 30-34 year women in the Egypt Demographic and Health Survey (EDHS) 2014. The discrepancy may be due to the fact that SYPE 2014 includes both male and female respondents; thus, some of the male respondents may not be aware of their wife's use of contraception. The most commonly reported contraceptive method currently used among married respondents was the intrauterine device (IUD) (23.2\%) followed by oral contraceptive pills (14.2\%) and injectables (6.8\%). Raising young people's awareness of the benefits of family planning for themselves, their families, and their communities should be a priority and should target both male and female youth.

\section{Education}

\section{WHO ATTENDED SCHOOL AND WHO MISSED OUT?}

Primary school enrollment is now nearly universal. More than 95\% of youth aged 13-18 in 2014 had attended school. However, many youth do not complete mandatory basic education. The percentage of young people completing preparatory education by age 16 ranges from $86.9 \%$ in Urban Lower Egypt to $69.1 \%$ in the Frontier Governorates. ${ }^{6}$

Among youth aged $25-29$ in $2014,18.4 \%$ of women and $7.4 \%$ of men were illiterate.

6 With the adoption of the January 2014 constitution, secondary education became mandatory (Egypt State Information Service, 2014), whereas previously only basic (primary and preparatory level) education was mandatory. On-time school entry occurs at age six. The primary stage of education consists of six grades, and upon completion of primary education students are expected to proceed to preparatory education, starting at age 12, for an additional three years. See Chapter 2 in the SYPE report (Roushdy and Sieverding 2015) for detailed information on the potential paths students might follow as they progress through the Egyptian education system. 


\section{INTERGENERATIONAL EDUCATION}

MOBILITY

Although young people tend to be bettereducated than their parents, the education young people achieve is closely linked to their parents' education. The chance that a young person with an illiterate mother attends university is $12.0 \%$, while the chance that a young person with a university-educated mother attends university is $93.0 \%$. Thus, the education system is falling short of the goal of providing equal opportunities for all youth.

\section{SCHOOL QUALITY}

Grade repetition and absenteeism are signs of inefficiencies and quality problems in the education system. Two of the most common reasons for being absent from school among young people aged 13-35 who were in school in 2014 were "do not benefit from school" (27.7\%) and "to study outside of school" (22.1\%). ${ }^{7}$

Rote memorization is a much more common approach to teaching than critical thinking. While $40.4 \%$ of students report teachers "always" only want students to memorize, just $10.5 \%$ report that the teachers always encourage students to form their own point of view, and only $9.5 \%$ report that the teachers always encourage students to express their opinions.

Results show that private lessons and other forms of supplemental education are increasingly common. For instance, while $47.5 \%$ of young people aged 30-34 in 2014 took private lessons or participated in support programs when they were in preparatory, $59.5 \%$ of those aged 13-17 in 2014 did so.

7 Reasons for being absent from school are reported by students who were enrolled in school during the SYPE 2014 interview, but were absent for one or more days during the current school semester.
Egypt has made enormous progress

over the past several decades in

ensuring that young people enter

school, but the challenge for Egypt now

is to ensure that children succeed and

\section{learn in school.}

Many youth who completed less than a primary education are not literate; around $50 \%$ of youth who attained five years of school cannot read, $50 \%$ cannot write, and $40 \%$ cannot do basic math (Figure 4). Since youth may drop out of school because they have difficulty with the material, this does not necessarily mean that half of the youth approaching the end of primary are illiterate, but it is a troubling sign in terms of the quality of the school system.

FIGURE 4 Literacy outcomes and literacy class attendance by years of school completed, for youth with less than a secondary education (\%), 2014

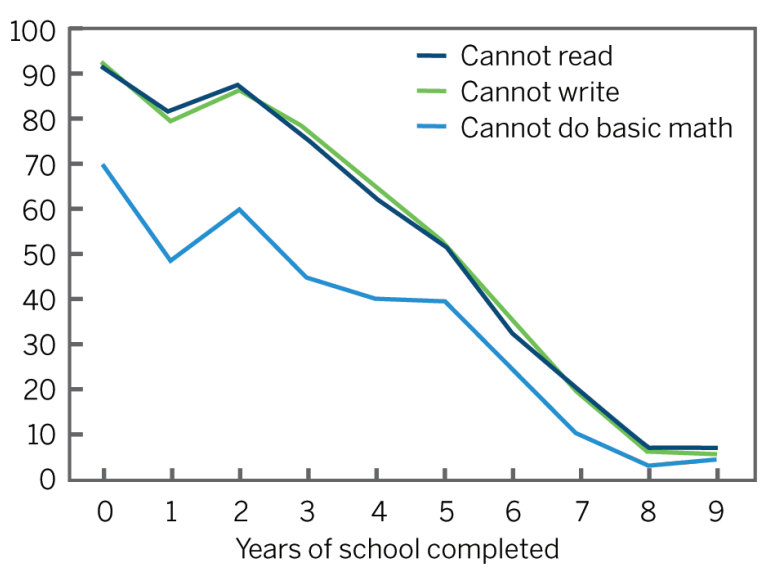

Note: Based on years attended, taking into account that some youth attended five-year primary and some youth attended six-year primary. 


\section{Employment}

\section{LABOR FORCE PARTICIPATION}

Labor force participation for young people aged $15-29$ years decreased slightly from $37.9 \%$ in 2009 to $36.6 \%$ in 2014. Young men's labor force participation declined from $61.4 \%$ to $57.8 \%$, whereas the rate among female youth remains similar to the 2009 level (13.4\% in 2009 versus $13.3 \%$ in 2014), though markedly lower than that of males.

Among nonstudents aged 15-29, a similar decline in total labor force participation was observed from $51.7 \%$ in 2009 to $49.6 \%$ in 2014 . Labor force participation declined from $86.4 \%$ in 2009 to $79.4 \%$ in 2014 among nonstudent male youth, while participation stayed around the 2009 level (18.0\%) among nonstudent female youth in 2014.

In 2009, the nonstudent female labor force participation rate among those aged 15-29 was only $7.1 \%$ in rural Upper Egypt and $9.9 \%$ in the Frontier Governorates. However, in 2014 female activity almost doubled in rural Upper Egypt, reaching $13.5 \%$. Female labor force participation also increased in the Urban Governorates and the Frontier Governorates, but the other regions experienced a decline in female labor force participation rates between 2009 and 2014 (Figure 5).

The male labor force participation rate declined across all regions of Egypt, with the largest drop in urban Lower Egypt. Male participation is now lowest in urban Lower Egypt and urban Upper Egypt, at $75.3 \%$ and $76.6 \%$ respectively.

\section{EMPLOYMENT STRUCTURE}

Young women and men (15-29) both experienced a decline in their employment-to-population ratio between 2009 and 2014 (from 9.4\% to $9.0 \%$ and from $54.0 \%$ to $52.4 \%$, respectively).
Young workers (aged 15-29) experienced a notable decline in wage work in 2014 (77.2\%) as compared to 2009 (87.9\%); correspondingly, participation in nonwage work (self-employed, employer, or unpaid family worker) almost doubled (from $12.1 \%$ in 2009 to $22.8 \%$ in 2014).

An important share of wage-earning male and female youth (aged 15-29) were still engaged in informal jobs, with neither a contract nor social insurance benefits, albeit declining from 43.5\% in 2009 to $30.6 \%$ in 2014 (Table 2).

This notable decline in youth participation in informal-sector employment from 2009 to 2014 was not associated with an equivalent increase in the share of government or formal

FIGURE 5 Nonstudent labor force participation rate of youth aged $15-29$, according to region, by gender, 2009 and 2014 (\%)

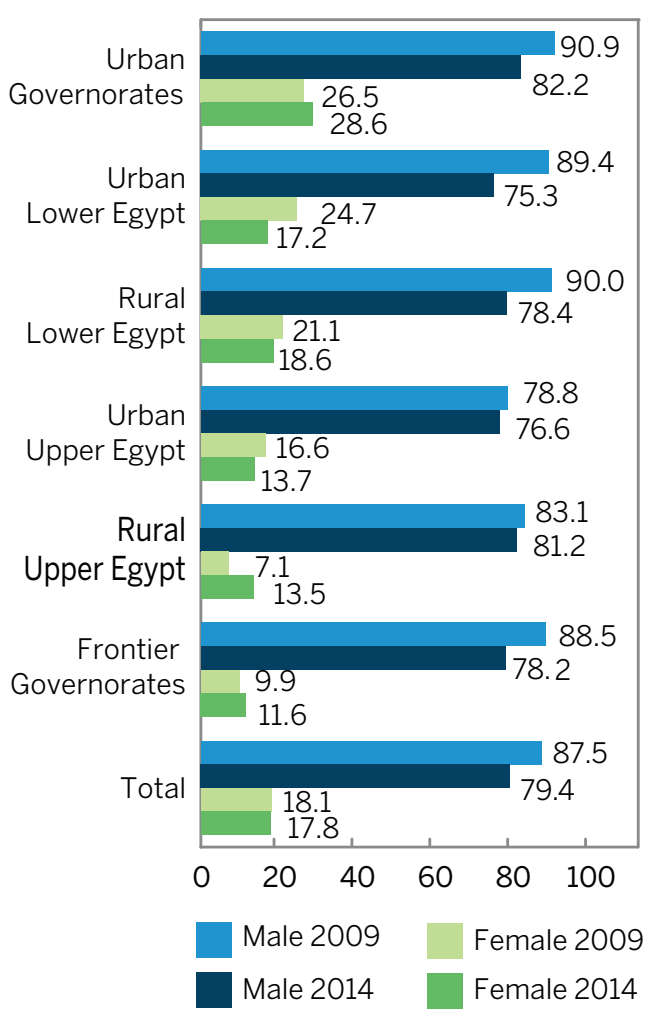


TABLE 2 Distribution of employed youth, by type of employment, 2009 and 2014 (\%)

\begin{tabular}{lrr}
\hline & $\mathbf{2 0 0 9}$ & $\mathbf{2 0 1 4}$ \\
\hline Public & 13.9 & 13.6 \\
Formal private regular wage & 8.7 & 6.8 \\
Informal private regular wage & 43.5 & 30.6 \\
Irregular wage & 21.7 & 26.3 \\
Unpaid family worker & 8.5 & 10.7 \\
Employer & 1.1 & 5.9 \\
Self-employed & 2.5 & 6.2 \\
\hline
\end{tabular}

wage work, but rather with an increase in the share of irregular wage work (from $21.7 \%$ to $26.3 \%$ ) and nonwage work (from $12.1 \%$ to $22.8 \%$ ). This shift to irregular wage jobs, which is the most vulnerable form of employment, is often correlated with poverty.

\section{ENTREPRENEURSHIP}

The percent of youth who are employers or self-employed increased between 2009 and 2014 from $3.7 \%$ to $13.1 \%$ among employed men and from $3.2 \%$ to $5.7 \%$ among employed women.

When youth who started their own business were asked why they were interested in being entrepreneurs, a large proportion (42.8\%) said they were motivated by the greater independence provided by self-employment. Nevertheless, another $37.2 \%$ of male youth and $29.2 \%$ of female youth reported that their inability to find a wage job was one of the main reasons behind their entrepreneurial activities.

\section{UNEMPLOYMENT}

Young people's (aged 15-29) standard unemployment rate has declined from $16.1 \%$ in 2009 to about $13.3 \%$ in 2014 . This was mainly due to the decline in the male youth unemployment rate from $12.9 \%$ to $9.3 \%$ during the five-year period. In contrast, the female youth unem-
The drop in the unemployment rate

in Egypt (from $16.1 \%$ in 2009 to

$13.3 \%$ in 2014) was not associated

with an increase in employment

levels. Rather, it was a result of the

increased number of youth who got

discouraged and left the labor force. ployment rate increased from $31.3 \%$ in 2009 to $32.3 \%$ in 2014.

Unemployment remained a serious problem for educated youth. As in 2009, the unemployment rate was highest among those who completed post-secondary education, as well as among youth with a university education or higher.

The percentage of youth reporting that their unemployment was due to the unavailability of work declined from $69.2 \%$ in 2009 to $58.3 \%$ in 2014. However, the percentage of both men and women reporting not finding jobs that match their experience or qualifications increased from $8.0 \%$ in 2009 to $13.8 \%$ in 2014 . Young women in 2014 were also twice as likely as in 2009 to say that they could not find a job in a suitable organization. This might be due to the heightened sense of insecurity that followed the events of January 25, 2011 and June 30, 2013.

Panel data analysis of the two waves of SYPE shows that the decline in youth labor force participation between 2009 and 2014 was driven by large shares of the 2009 students being out of the labor force (33.2\%), being unemployed but actively seeking work (27.8\%), and discouraged unemployed youth transitioning into inactivity rather than to employment (31.6\%) during the last five years. 


\section{International migration aspirations}

Despite political and economic instability in Egypt during the transition period, the percentage of youth hoping to migrate internationally in the future held relatively steady between the two surveys. About $17.2 \%$ of youth aged $15-29$ aspired to migrate within the next five years in SYPE 2014, compared with $18.3 \%$ of youth in the 2009 survey.

The vast majority of youth (93.0\%) who aspired to migrate said they would like to migrate only temporarily: the mean duration of intended stay abroad was five years.

\section{Economic factors were the main}

\section{drivers of young people's aspirations}

\section{to migrate and not the political and}

\section{security climate.}

\section{WHO ASPIRES TO MIGRATE?}

Egyptian males aged 15-29 were three times more likely to aspire to migrate (25.8\%) than female youth (7.8\%). Migration aspirations peaked at $28.1 \%$ for young men aged $18-24$ (Figure 6).

Male youth (aged 15-29) from rural areas were more likely to aspire to migrate (28.3\%) than those in urban areas (23.3\%) and those in informal urban housing (16.2\%). Furthermore, the percentage of male youth aged 15-29 interested in migration was highest for university graduates at $30.3 \%$, compared to $17.2 \%$ among illiterate youth.

\section{WHY YOUNG PEOPLE ASPIRE TO MIGRATE AND TO WHERE}

Economic factors were the main drivers of migration. Among youth aged 18-29 who wish to migrate, low income was the main push factor out of Egypt (43.9\%). Two-thirds of youth blamed lack of job opportunities in Egypt for
FIGURE 6 Long-term migration aspirations among youth aged 13-35, in 2009 and 2014 (\%)

\section{9 (15-29-YEAR-OLDS)}

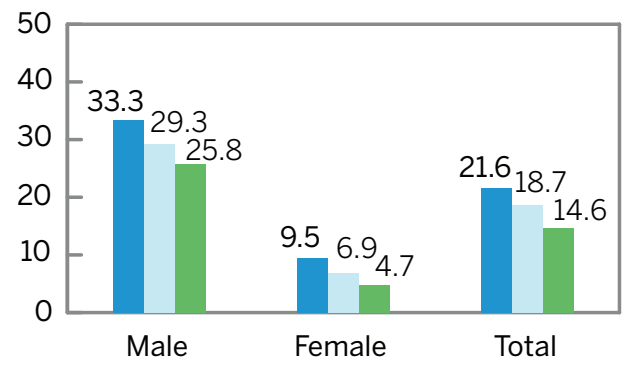

\section{4 (15-29-YEAR-OLDS)}

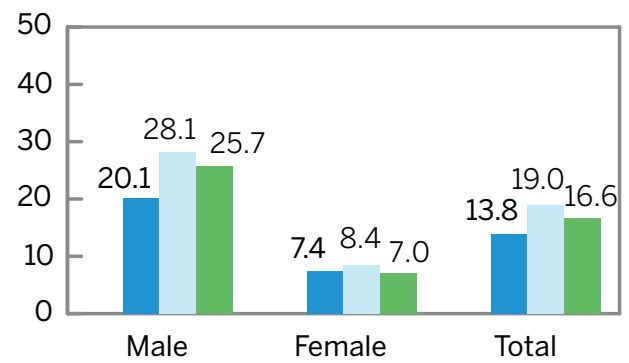

2014 (13-35-YEAR-OLDS)

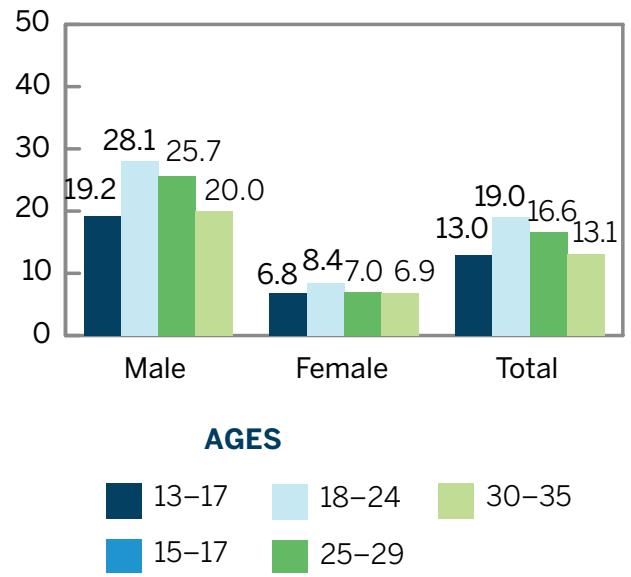

pushing them to aspire to migrate. Poor living conditions in Egypt (48.9\%) were another common push factor. Only $10.1 \%$ of youth blamed the political and security circumstances in Egypt for driving them to want to leave (multiple responses were allowed for this question).

About $87.5 \%$ of aspiring migrant youth aged $15-$ 29 said they would choose to go to Arab countries (especially Saudi Arabia), while $12.5 \%$ indicated aspirations to migrate to Western countries. 


\section{Marriage and family formation}

A large percentage of males marry in their late 20 s and early 30 s. In $2014,41.4 \%$ of male youth aged $25-29$ were married, compared to $74.8 \%$ of male youth aged 30-35. Still, a quarter of young men remain never married in their early 30 s.

Female youth marry at younger ages; $3.7 \%$ were married at ages $15-17,32.4 \%$ at $18-24,72.7 \%$ at $25-29$, and $84.3 \%$ at $30-35$.

\section{EARLY MARRIAGE}

Female youth in rural areas continue to face the greatest risk of early marriage. Among married female youth aged 25-29 in 2014, 33.3\% of those in rural Upper Egypt and $18.8 \%$ of those in rural Lower Egypt had been married by age 18 (Figure 7).

\section{CHARACTERISTICS OF YOUNG MARRIAGES}

Young women also have less say in their decision to marry: $37.4 \%$ of young married women and $14.2 \%$ of young married men said that somebody else arranged their marriage. Conversely, $54.1 \%$ of young men decided for themselves whom to marry, compared to $20.2 \%$ of young women.

FIGURE 7 Percentage of married female youth aged 25-29 who were married before age 18 , by region, 2009 and 2014 (\%)

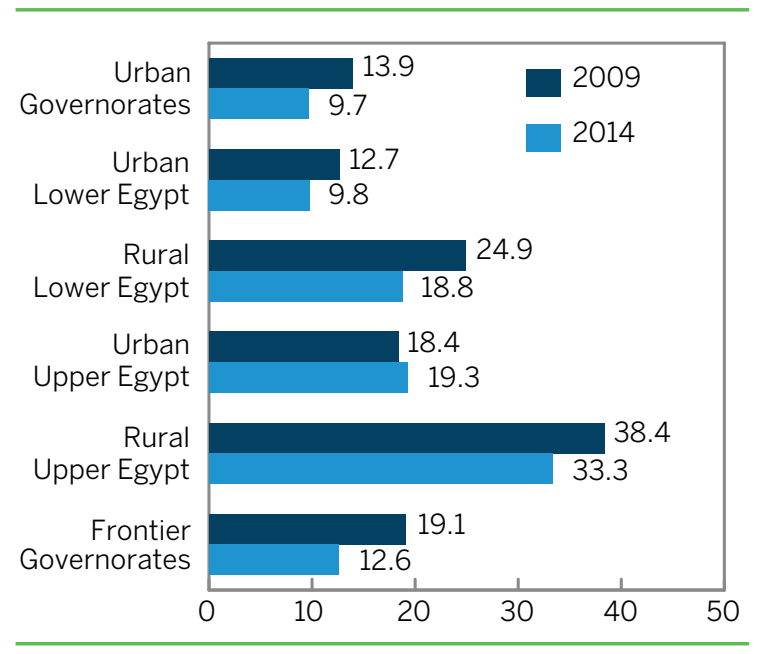

\section{Desired fertility has risen among both} married and never-married youth between 2009 and 2014 .

Better-educated and wealthier youth tended to report higher levels of marital communication and mutual understanding. For example, 85.5\% of youth with a university education reported feeling "free and independent" in their marriage, compared to $61.5 \%$ of illiterate youth. Also, more males (82.1\%) than females (72.7\%) felt "free and independent" in their marital relationship.

Youth married between 2010 and 2014 reported an average cost of marriage of about 38,500 EGP, compared to about 30,500 EGP among youth married between 2005-2009. When comparing the real values, the cost of marriage appears to have declined by almost one-fifth between two marriage cohorts. ${ }^{8}$

Never-married youth aged 15-29 desired an average of 2.6 children in 2009, compared to 2.9 in 2014. Currently married 15-29-year-olds desired 2.8 children in 2009 and 3.1 in 2014 (Figure 8).

8 Exchange rate is 1 US dollar $=7.6$ EGP as of June 2014

FIGURE 8 Desired number (mean) of children among married and unmarried youth aged 15-29, by gender, 2009 and 2014

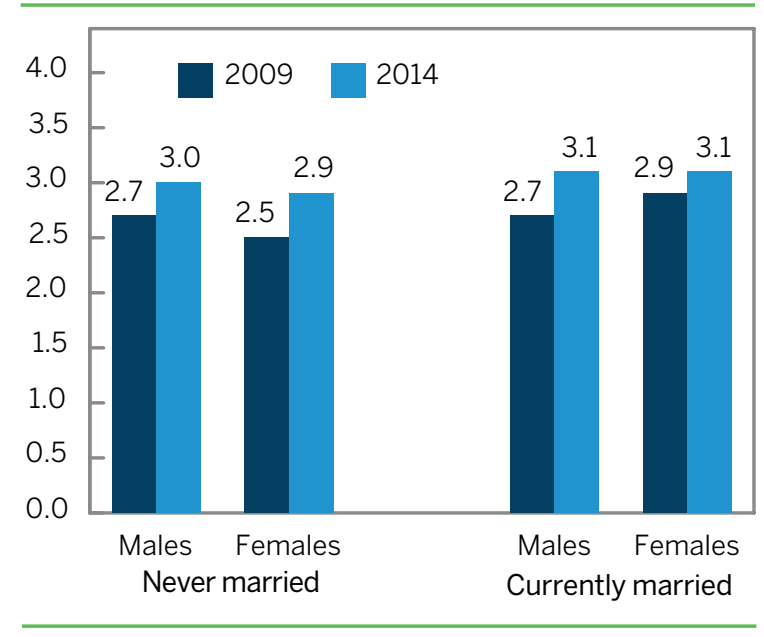




\section{Political and civic participation}

\section{YOUTH VOTING BEHAVIOR}

Data from SYPE 2009 indicate that only 16\% of respondents of voting age had ever voted in an election. Results from SYPE 2014 show youth participation in national elections has increased substantially since 2009, with turnout ranging from $52 \%$ to $65 \%$ in referendums and elections that took place between 2011 and 2012.

\section{YOUTH PARTICIPATION IN POLITICAL EVENTS}

Youth participation in political activities (protesting, supporting protesters, strikes, participating in neighborhood watches, political and electoral organizing, etc.) between January 25, 2011 and the SYPE 2014 interview was low, with only 7.4\% of youth reporting engaging in such activities. There was a substantial gender gap in participation in political activities, with $13.1 \%$ of male respondents participating compared to $1.5 \%$ of female respondents.

Involvement in political activity varied greatly by residence; $13.9 \%$ of youth from the Urban Governorates participated in any form of activity, compared to lows of $2.6 \%$ in the Frontier Gov-

FIGURE 9 Young people's reports of their own and their networks' participation in any revolutionary activity, by gender, 2014 (\%)

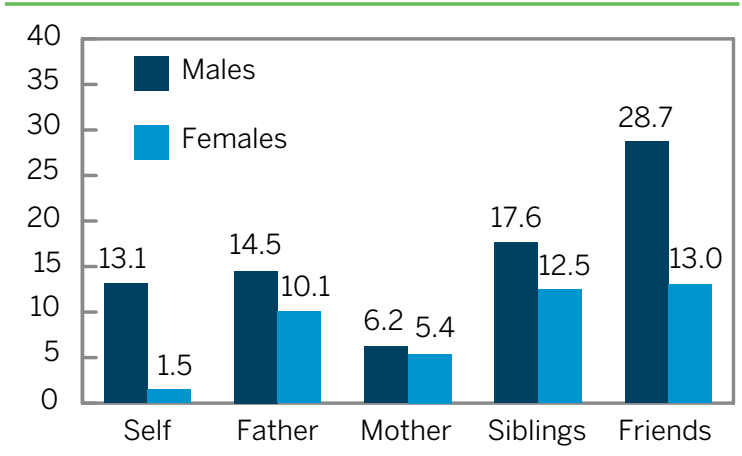

ernorates and rural Upper Egypt, and 2.1\% in urban Upper Egypt.

A positive correlation exists between young people's education level and the likelihood of participating in some form of political activism. Illiterate youth were the least active, with a participation rate of $2.6 \%$, while those with university and graduate-level education reported the highest level of participation at $12.2 \%$.

Whereas young people's self-reported involvement in any revolutionary activity is low, respondents indicated higher rates of participation for their family members and friends (Figure 9). ${ }^{9}$

\section{YOUTH VOLUNTEERISM}

Youth participation in volunteer activities remains low. In SYPE 2009 , only $2.8 \%$ of youth ever volunteered during the year prior to the interview. In SYPE 2014, only 3.6\% of youth reported that they had ever volunteered since the 2009 interview.

\section{INTERNET AND MEDIA USE}

Young people's internet and media use increased dramatically between 2009 and 2014; in 2014 , about $25 \%$ of youth aged $15-29$ reported having ever used the internet, compared to less than $10 \%$ in 2009 . Also, about $80 \%$ of youth reported that at least one type of media was important or very important to them for getting information about the January 25 revolution. In contrast, in 2009, only about $30 \%$ of youth aged 15-29 reported that they ever used any form of media as a source of news.

9 We suspect that youth underreported their own activism given the politically sensitive climate from late July 2013 through early 2014 during which SYPE data were collected. This period included crackdowns on certain political parties, as well as the passage of a restrictive protest law in November 2013. 
On a scale from 1 to 10 , youth rated television as their most important source of information regarding the January 25 revolution, with a rating of 8.2. This was followed by radio and newspapers (4.7), internet and Facebook (4.4), and Twitter (3.9).

\section{YOUNG PEOPLE'S FEELINGS ABOUT THE} FUTURE

About $71.5 \%$ of youth in 2014 stated that raising living standards should be the top priority for the country, and $42.9 \%$ indicated that fighting corruption should be the second priority (Figure 10).

When asked about the top challenges facing the country, $63.2 \%$ of youth reported lack of security as the first challenge and $37.9 \%$ stated the economic crisis as the second challenge.

To understand how to increase young people's engagement in national development and civic life, it is crucial to understand their opinions on social affairs. In SYPE 2014 youth were asked to evaluate, on a scale from 1 to 10 , the prevalence of certain values in Egyptian society. On average,

FIGURE 10 Youth opinion on the top two priorities for the country, 2014 (\%)

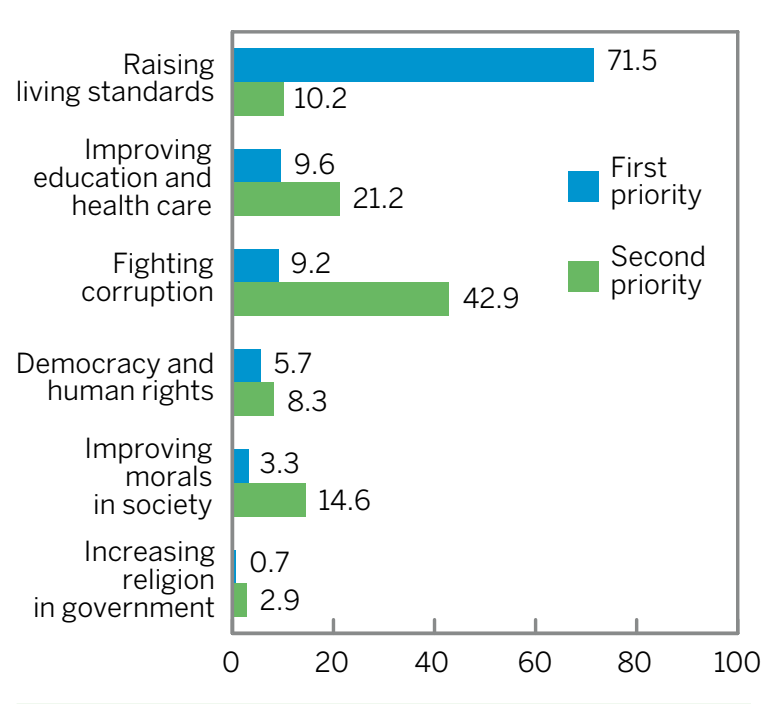

Internet use among youth increased dramatically in the five years between surveys, jumping from $10 \%$ in 2009 to $25 \%$ in 2014. youth ranked being financially well-off and well educated as the two most important values in society, with ratings of 6.8 and 6.4 . In contrast, youth felt that political tolerance (4.5), transparency in transitions (4.5), and the rule of law (5.0) were not valued as highly.

Youth were also asked to rate their feelings about their lives and the condition of the country in the past several years (before January 25th 2011, from January $25^{\text {th }}$ to June $30^{\text {th }} 2013$, and after June $30^{\text {th }}$ 2013) and five years after the time of the survey. While respondents report fluctuations in their overall well-being and the condition of Egypt in the past several years, youth display considerable optimism about the future, both for themselves and the country.

\section{Young people's attitudes toward gender roles}

\section{HOUSEHOLD DYNAMICS}

Youth in SYPE 2014 demonstrated highly conservative outlooks on gender roles and dynamics within the household: among respondents aged 15-29, 60.6\% believed that brothers should have authority over their sisters (Figure 11), 47.4\% agreed that husbands should have full control over household spending, and $76.3 \%$ stated that a wife must obtain permission from her husband for all activities.

Male youth consistently held more conservative views than females. Males (67.5\%) were more 


\section{Gender attitudes remained highly} conservative among Egyptian youth: More than three-fourths agreed that a wife must obtain permission from her husband for all activities.

likely than their female counterparts (53.1\%) to support a brother's authority over his sisters (Figure 11). About 55.2\% of male youth believed that financial decision making should be solely in the hands of the husband, compared to 38.9\% of female youth. Also, male respondents were slightly more likely (78.8\%) than female respondents $(73.6 \%)$ to agree that a woman must obtain permission from her husband "before doing anything".

\section{ACCESS TO EDUCATION, EMPLOYMENT, AND ELECTORAL POLITICS}

The majority of respondents continued to support giving men job priority. Over half (60.4\%) of respondents aged 15-29 believed that when jobs are scarce, male applicants should be given priority.

FIGURE 11 Responses of youth aged 15-29 to questions about gender dynamics, 2014 (\%)

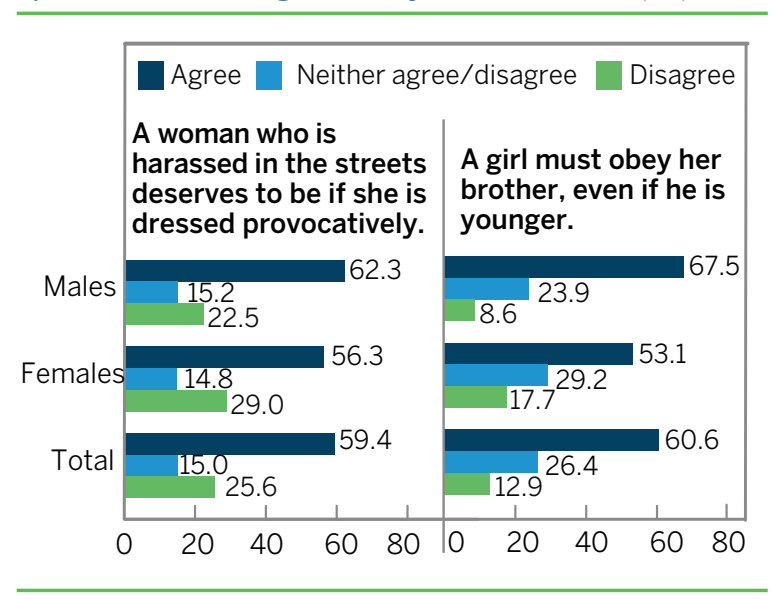

However, we found more egalitarian outlooks in the domains of education, electoral politics, and a woman's right to divorce. Among all respondents aged 15-29, 56.7\% supported gender equality in education, $81.6 \%$ agreed with the right to vote for female family members, and $71.4 \%$ endorsed a woman's right to separate from her husband.

\section{RIGHT TO ASK FOR DIVORCE AND GENDER- BASED VIOLENCE}

Although the majority of respondents supported a woman's right to divorce (63.7\% in 2009 vs. $71.4 \%$ in 2014), evidence from SYPE respondents suggests that divorced women are not viewed positively in Egypt. Almost two-thirds (63.7\%) of 2014 respondents (aged 15-29) felt that society does not respect divorced women.

About $64.9 \%$ of SYPE 2014 respondents (aged 15-29) believed that a man could justifiably beat his wife if she "talked to another man." As was the case in 2009, young men in 2014 were more likely than young women to approve of wife battery in each circumstance. For example, $70.9 \%$ of male respondents and $58.4 \%$ of female respondents aged 15-29 thought that a man could beat his wife if she "talked to another man."

Moreover, almost $60 \%$ of respondents aged 15-29 agreed that women in public "deserve" to be sexually harassed if their clothing is "provocative" (Figure 11). Unsurprisingly, male respondents (62.3\%) were more likely than female respondents (56.3\%) to assert that women dressed "provocatively" in public "deserve" to be harassed; nevertheless, over one-half of female respondents aged 15-29 agreed with the statement in 2014. 


\section{Conclusion and policy implications}

SYPE panel data from 2009 and 2014 provide important insights into the experiences of Egyptian young people in 2014 and identify important issues facing youth in the country's new political environment. Results show that while youth participation in volunteerism and groups remains quite low, young people's voting behavior has changed significantly, with consistently high voter turnout in elections and referendums in 2011-2013. Also, SYPE 2014 recorded low rates of youth participation in revolutionary activities. In contrast, youth internet and media use since January 2011 rose sharply from the figures reported in 2009.

When asked about pressing issues facing Egypt, respondents emphasized the importance of improving quality of life and fighting corruption, and young people appear most concerned with the lack of stability in the country. Although respondents report fluctuations in their overall well-being and in the condition of Egypt in the past several years, many are optimistic about the future, both for themselves and the country.

The survey also provides evidence that youth labor market conditions have deteriorated during the transition period. The share of employment in the government and in the formal and informal private wage sectors has declined. This seems to have led many youth to shift to irregular wage jobs, the most unstable form of employment. Migration aspirations among young people changed little between the two SYPE surveys. Responses from the SYPE 2014 show that youth prefer a larger family size than they did in 2009 , and contraceptive use was low among married SYPE respondents.

Results in 2014 confirm findings from 2009 that certain segments of young people in Egypt are consistently more disadvantaged when it comes to key life opportunities. Young people, particularly young women, in rural areas have poorer educational outcomes, increased risk of negative practices such as early marriage and female genital mutilation/cutting, and lower levels of engagement in political and civic life. Young women are also constrained by highly conservative gender attitudes that persist regarding their roles both inside and outside the home.

When data from both survey years are taken together, it becomes clear that several areas require attention in order to provide a brighter future for Egypt's young people. Difficult economic conditions in Egypt since 2011 have had especially negative effects on youth. In addition to poorer labor market outcomes, young people's perceptions of the challenges and priorities facing their peers and the country show a strong preoccupation with ensuring a basic livelihood. Under these circumstances, ensuring better employment opportunities for youth must be a key priority during the transitional period.

Although development programs target the most disadvantaged populations, policies to promote equal opportunity for all youth are a more sustainable and far-reaching means to change outcomes on a national scale. The increase in the ideal number of children above the national target of 2.1, combined with the 
low use of family planning, necessitates urgent action. Continued population growth in Egypt could put more pressure on Egypt's already weakened economy and could lead to further deterioration in labor market conditions for future generations.

SYPE 2014 provides one of the first nationally representative pictures of young people's engagement with the political and social processes that will shape Egypt's future. Despite a dramatic increase in young people's participation in elections, many still do not engage in other areas of civic life such as volunteering, group membership, and social discussion of current events. In order for youth to contribute further to Egypt's transition, measures are needed to foster their continued transition toward active citizenship.

\section{REFERENCES}

Egypt State Information Service. 2014. "Constitution of The Arab Republic of Egypt" (English Translation). Retrieved from http://www.sis.gov. eg/ Newvr/Dustor-en001.pdf.

Roushdy, Rania and Maia Sieverding. 2015. Panel Survey of Young People in Egypt (SYPE) 2014: Generating Evidence for Policy, Programs, and Research. Cairo, Egypt: Population Council. 


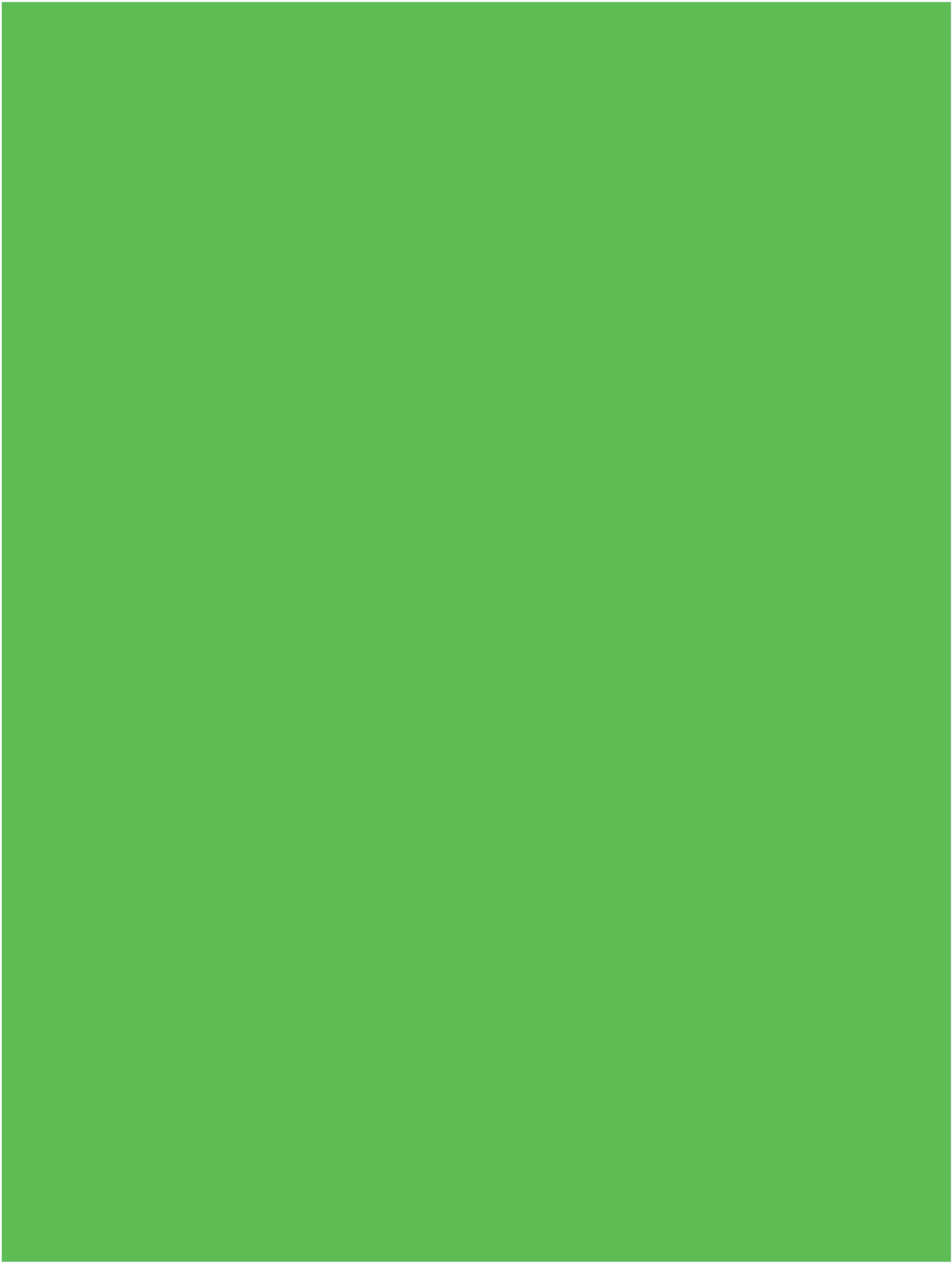




\section{porvunton COUNCIL \\ Ideas. Evidence. Impact.}

Population Council

One Dag Hammarskjold Plaza

New York, NY 10017

Population Council/Egypt

59 Misr-Helwan Agricultural

Road, Maadi

PO Box 168, Maadi

Cairo, Egypt 11431

Tel. +20 225255968

Fax: +20 225255962

popcouncil.org 